\title{
Nursing Activities Score: nursing work load in a burns Intensive Care Unit ${ }^{1}$
}

\author{
Marcia Bernadete Camuci² \\ Júlia Trevisan Martins ${ }^{3}$ \\ Alexandrina Aparecida Maciel Cardeli ${ }^{3}$ \\ Maria Lúcia do Carmo Cruz Robazzi ${ }^{4}$
}

\begin{abstract}
Objective: to evaluate the nursing work load in a Burns Intensive Care Unit according to the Nursing Activities Score. Method: an exploratory, descriptive cross-sectional study with a quantitative approach. The Nursing Activities Score was used for data collection between October 2011 and May 2012, totalling 1,221 measurements, obtained from 50 patients' hospital records. Data for qualitative variables was described in tables; for the quantitative variables, calculations using statistical measurements were used. Results: the mean score for the Nursing Activities Score was $70.4 \%$ and the median was $70.3 \%$, corresponding to the percentage of the time spent on direct care to the patient in 24 hours. Conclusion: the Nursing Activities Score provided information which involves the process of caring for patients hospitalized in a Burns Intensive Care Unit, and indicated that there is a high work load for the nursing team of the sector studied.
\end{abstract}

Descriptors: Workload; Nursing; Intensive Care Units; Burn Units.

\footnotetext{
${ }^{1}$ Paper extracted from master's thesis "The nursing workload in Intensive Care Unit of Burn Care Center according to Nursing Activities Score", presented to Universidade Estadual de Londrina, Londrina, PR, Brazil.

2 Master's student, Universidade Estadual de Londrina, Londrina, PR, Brazil.

${ }^{3} \mathrm{PhD}$, Adjunct Profesor, Universidade Estadual de Londrina, Londrina, PR, Brazil.

${ }^{4} \mathrm{PhD}$, Full Professor, Escola de Enfermagem de Ribeirão Preto, Universidade de São Paulo, WHO Collaborating Centre for Nursing Research Development, Ribeirão Preto, SP, Brazil.
}

Corresponding Author:

Marcia Bernadete Camuci

Rua Brasil, 649, Apto. 1004, Bloco 3

Centro

CEP: 86010-200, Londrina, PR, Brasil

E-mail: mbcamuci@sercomtel.com.br
Copyright (c) 2014 Revista Latino-Americana de Enfermagem This is an Open Access article distributed under the terms of the Creative Commons Attribution Non-Commercial License (CC BY-NC).

This license lets others distribute, remix, tweak, and build upon your work non-commercially, and although their new works must also acknowledge you and be non-commercial, they don't have to license their derivative works on the same terms. 


\section{Introduction}

In order to care for and treat people who have suffered burns from a wide variety of causes, with lesions differing in location, extent and depth, one needs a multiprofessional team and an appropriate place, such as a Center for Burns Treatment, which also includes the Burns Intensive Care Unit (ICU)(1).

The Burns ICU is considered a complex unit which brings together human resources and expensive specialized technological apparatus. It is necessary to have professionals available for this sector both qualitatively and quantitatively, due to the care required for the hospitalized patients. Because these are nursing professionals who care for the patients uninterruptedly over 24 hours, it is fundamental to assess their work load.

This evaluation is a way of making available a fair and efficient dimensioning of the human resources, affording the institutions planning which aims for benefits for all those involved, in particular the patients ${ }^{(2)}$.

The expression 'work load' is used as a method for calculating the workforce, that is, it is used regarding the demands of the labor and the analysis of the content of the different work activities(3).

The provision of nursing staff appropriate to the standard of attendance aimed for contributes to quality care for the patients, and, as a consequence, reduction of the burden which can be present in the work, making it less stressful and safer for professionals, institutions, and patients.

Indicators of the care demands are essential as requirements to ensure quality of care and support the quantification of the personnel in the different hospital units, principally in ICU, due to there being a heavier workload because of the characteristics inherent to the patients found there ${ }^{(4)}$.

Instruments have been created with the aim of quantifying the nursing work load and, consequently, contributing to the appropriate dimensioning of staff for assisting the patients. Among these, the Nursing Activities Score (NAS) stands out ${ }^{(5)}$.

The NAS is a valuable tool for measuring work load, and can contribute to the appropriate dimensioning of nursing workers in ICU. Its use as a tool in ICU, however, has not been publicized in the literature(2). In addition to this, the literature has indicated that the risks related to the insufficient number of nursing professionals, due to the different practice locations and groups of workers who undertake the care, these being the central elements which must be investigated in each specific situation(6).

As a result, the implementation of a system for measuring and evaluating work load has been indicated as important for planning the number of nursing professionals $^{(7)}$. Thus, investigating the indicators of nursing work load allows managers to apply methods for dimensioning the professionals, with the aim of ensuring quality and the safety of the care, the workers, and the health institutions ${ }^{(8)}$.

In the light of the above, it was proposed to apply the NAS in the Burns ICU of a public teaching hospital, with the objective of evaluating this unit's nursing work load. This study could contribute to managers' being able to plan human resources in appropriate numbers, as well as the quality of care given in the Burns ICU.

\section{Method}

This is an exploratory, descriptive and crosssectional study, with a quantitative approach, undertaken in a six-bed Burns ICU in a teaching hospital in the north of the Brazilian state of Paraná (PR). The researchers consulted the hospital records of 50 patients admitted consecutively to the Burns ICU in the period between October 4th 2011 and 30th May 2012, aged 18 years old or over, and who remained hospitalized there for a minimum period of 24 hours. Re-admissions were excluded.

The period extending from seven o'clock in the morning of one day to seven o'clock in the morning of the next day was considered as 24 hours. In the event of hospitalization, data was collected from the time of admission until seven o'clock in the morning, regardless of whether 24 hours was completed. On the day of discharge or death, data was collected from seven o'clock in the morning until when the patient left the sector, irrespective of whether 24 hours was completed.

A two-part instrument was used for data collection. The first part collected data such as: age, sex, outcome (discharge from ICU or death) and the length of hospitalization in days; in the second, the NAS instrument was applied for 241 consecutive days in the six beds of the Burns ICU, totalling 1,221 measurements obtained from the hospital records of 50 patients hospitalized in this sector.

The NAS was translated to Portuguese and validated in that language in 2002, and provides 
data on activities undertaken by the nursing team by shift(4) and is considered able to accurately assess the nursing work load in Adult ICU(5). This instrument is made up of seven major categories of care: basic activities; ventilatory, cardiovascular, renal, neurological and metabolic support; and specific interventions. It also came to cover monitoring and control, hygiene procedures, mobilization and positioning of the patient, support and care for patients and their family members, and administrative and managerial tasks. It is made up of 23 items with 32 nursing activities ${ }^{(9)}$. Each activity has a score which corresponds to the percentage of the time spent on direct care undertaken in the 24-hour period. The total score can reach, at the most, $176.8 \%$ per patient. The total score results from the sum of the score of each item and allows one to calculate the amount of time spent with the nursing activities in the care for the patient ${ }^{(5)}$.

The statistical procedures were carried out using descriptive analysis, that is, for the qualitative variables the data was described in tables; while for the quantitative data, calculation of the statistical measurements was used. The data was organized and stored in Excel 2007 electronic spreadsheets. The Statistical Package for the Social Sciences (SPSS) ${ }^{\circledR}$ program, version 19.0, was used for analyzing the data.

The study was approved by the Research Ethics Committee of the State University of Londrina (UEL), under decision n. 214/2011 and the Certificate of Presentation for Ethical Consideration (CAAE) 0187.0.268.000-11 was issued.

It is emphasized that for undertaking this study, the "Terms of Confidentiality" were filled out and signed, in which the researchers accepted the commitment to maintain confidentiality regarding all the information, technical and otherwise, related to the research project, including respecting confidentiality and identity.

\section{Results}

There was a predominance of male patients (74\%); age varied between 18 and 76 years old (mean of 41 years old). Regarding the depth of the burn, it was identified that $70 \%$ of the patients had third-degree burns; the length of hospitalization varied from 2 to 97 days (mean of 24 days); and the patients' discharges (74\%) outweigh the deaths (26\%).

In relation to the nursing work load, resulting from the application of the NAS, the mean found was $70.4 \%$, with a minimum value of $52.5 \%$, maximum of $97 \%$, and median of $70.3 \%$. Knowing that each point on the NAS corresponds to 14.4 minutes, it was ascertained that the patients in the aforesaid study needed a mean of 16.9 hours of nursing care in the 24 hour period ( minimum $=12.6$ hours and maximum $=23.2$ hours). This data allows one to suggest that there is a high work load for the nursing team of the Burns ICU.

The frequency with which the activities described in the NAS instrument were recorded is demonstrated in Table 1 . It was identified that $100 \%$ of the patients were scored for in the following items: Item 2 - laboratory investigations; and Item 3 - medication, apart from vasoactive drugs.

The scores with percentages above 50\% corresponded to nursing interventions related to Item 17 - quantitative measurement of the urinary output (99.6\%); Item 11 - treatment for improvement of pulmonary function (97.2\%); Sub-item 8.a - routine tasks (91.8\%); Item 21 - enteral feeding $(87.7 \%)$; Item 9 - respiratory support (83.6\%); Item 5 - care for drains (74.6\%); Sub-item 7.a - Support and care for the family and patient for one hour (71\%); Sub-item $6 . \mathrm{b}$ - undertaking of mobilization and positioning more than three times in 24 hours or with two nurses in any frequency (69\%); Item 10 - care with artificial airways, orotracheal tubes (OTT) or tracheostomy (68.7\%); Subitem 1.b - presence at the bedside for two hours or more (68.3\%); Sub-item 4.a - hygiene procedures (51.4\%).

Table 1 - Distribution of the therapeutic nursing interventions according to the Nursing Activities Score. Londrina, PR, Brazil, 2011-2012

\begin{tabular}{lcc}
\hline \multicolumn{1}{c}{ Basic Activities of the Nursing Activities Score } & $\mathbf{n}$ & $\%$ \\
\hline 1- Monitoring and control & 42 & 3.4 \\
1. a - Vital signs and fluid balance* & 834 & 68.3 \\
1. b - At the bed-side for two hours or more* & 345 & 28.2 \\
1. c - At the bed-side for four hours or more* &
\end{tabular}


Tabela 1 - continuação

\begin{tabular}{|c|c|c|}
\hline Basic Activities of the Nursing Activities Score & n & $\%$ \\
\hline 2 - Laboratory investigations & 1221 & 100.0 \\
\hline 3 - Medication, apart from vasoactive drugs & 1221 & 100.0 \\
\hline \multicolumn{3}{|l|}{$4-$ Hygiene procedures } \\
\hline 4.a- Hygiene procedures* & 628 & 51.4 \\
\hline 4.b - Hygiene procedures for more than two hours* & 427 & 34.9 \\
\hline 4.c - Hygiene procedures for more than four hours* & 164 & 13.4 \\
\hline 5 - Drain care (apart from nasogastric tubes) & 911 & 74.6 \\
\hline \multicolumn{3}{|l|}{6 - Mobilization and positioning } \\
\hline 6.a - Undertaken up to three times in 24 hours* & 241 & 19.3 \\
\hline 6.b - Undertaken more than three times in 24 hours or with two nurses & 843 & 69.0 \\
\hline 6.c - Undertaken with three or more nurses* & 137 & 11.2 \\
\hline \multicolumn{3}{|l|}{7 - Support and care for the family and patient } \\
\hline 7.a - Support and care for the family and patient for one hour* & 867 & 71.0 \\
\hline 7.b - Support and care for family members for three hours or more ${ }^{*}$ & - & - \\
\hline \multicolumn{3}{|l|}{8 - Administrative and managerial tasks } \\
\hline 8.a - Routine tasks* & 1121 & 91.8 \\
\hline 8.b - Administrative and managerial tasks for two hours* & 100 & 8.1 \\
\hline 8.c-Administrative and managerial tasks for four hours or longer & - & - \\
\hline \multicolumn{3}{|l|}{ Ventilatory support } \\
\hline 9 - Ventilatory support & 1021 & 83.6 \\
\hline 10 - Care for artificial airways. Orotracheal tube or tracheostomy. Tracheostomy & 840 & 68.7 \\
\hline 11 - Treatment to improve pulmonary function & 1187 & 97.2 \\
\hline \multicolumn{3}{|l|}{ Cardiovascular support } \\
\hline 12 - Vasoactive medication & 419 & 34.3 \\
\hline 13 - Volemic replacement with more than $31 / \mathrm{m}^{2} /$ day & 213 & 17.4 \\
\hline 14 - Monitoring of left atrium. Pulmonary artery catheter & 2 & 0.1 \\
\hline 15 - Cardiorespiratory resuscitation, apart from precordial thump & 5 & 0.4 \\
\hline \multicolumn{3}{|l|}{ Kidney support } \\
\hline 16 - Hemofiltration. Dialytic techniques & 81 & 6.6 \\
\hline 17 - Quantitative measurement of urinary output (e.g. Permanent vesical catheter) & 1217 & 99.6 \\
\hline \multicolumn{3}{|l|}{ Neurological support } \\
\hline 18 - Measurement of intracranial pressure & - & - \\
\hline \multicolumn{3}{|l|}{ Metabolic support } \\
\hline 19 - Treatment for complicated metabolic acidosis/alkalosis & 1 & 0.1 \\
\hline 20 - Intravenous hyperalimentation & 18 & 1.4 \\
\hline 21 - Enteral feeding (Naso-enteral tube, jejunostomy) & 1072 & 87.7 \\
\hline \multicolumn{3}{|l|}{ Specific interventions } \\
\hline 22 -Specific interventions (intubation, surgery, endoscopy...) & 15 & 1.2 \\
\hline 23 - Specific interventions outside the Burns Treatment Unit & 444 & 36.3 \\
\hline
\end{tabular}

* The sub-items of items $1,4,6,7$ and 8 are mutually exclusive

\section{Discussion}

The predominance of male burns patients was noted, which was also ascertained in a study which analyzed the epidemiological profile of patients hospitalized in a BTU (Burns Treatment Unit) in the city of Belo Horizonte, which found that $62.5 \%$ of the patients were male(10).

Data similar to that of the present investigation was found in a study undertaken in the BTU of the Federal
University of São Paulo (UNIFESP), in which the mean age was 33.7 years old(11)

A study carried out in a BTU in Brasília, in which the mean length of hospitalization was 27 days ${ }^{(12)}$, was similar to the data found in the present investigation. It is inferred that the length of hospitalization may be related to the seriousness of the burn, as well as the body surface burnt.

Discharge from the Burns ICU was greater than deaths, and may be directly related to the seriousness 
of the patients' condition, as well as to the care given; however, the number of deaths which occurred is considered high. A rate considered high was also found in a study of a German BTU in which the death rate was $15 \%{ }^{(13)}$.

It is also suggested that the high rate of mortality found in this study may be related to the fact that a large number of the patients admitted to the Burns ICU unit of the HUL (Londrina University Hospital) originated from towns in the rural interior of the state of Paraná and had suffered the burn some days previously, thus contributing to the delay in initiating the specific therapy, which can have serious consequences and complications for the success of the treatment.

It is emphasized that appropriate volemic resuscitation initiated straight after the accident, represents an important gain in the survival of patients with large burns ${ }^{(14)}$. Age, and the extent and depth of the body surface burnt, are variables which can influence, to varying degrees, the occurrence of death ${ }^{(15)}$. It is therefore probable that these variables may have contributed to the high rate of mortality observed in the present study.

The activities evaluated by the NAS instrument in this study showed a high mean work load in the Burns ICU, which may suggest burden for this sector's nursing team, that is, an insufficient number of professionals. This data indicates a high demand for nursing care, demonstrating that to provide care within what is considered the ideal, it would be necessary to have one nursing professional to attend, comprehensively, only one patient per work period.

Thus, the importance is shown of the dimensioning of the nursing team, as the human resources, in quantity and quality, are essential for caring comprehensively for the patient and his or her family members, as well as for promoting appropriate conditions for the work of the nursing team, improving their quality of life and affording safety to the institution ${ }^{(16)}$.

This high mean was shown to be higher than that of the study undertaken in a general ICU in a medium-size* University Hospital in São Paulo, in which the mean of the NAS was $66.5 \%$ and remained above $50 \%$ throughout the period of hospitalization in that unit(17).

In another investigation carried out in a general adult ICU in a private hospital, also in the city of São Paulo, the data was similar to the present study's findings, in observing that the mean of the 24-hour NAS was $69.6 \%{ }^{(18)}$. Also in the city of São Paulo, another study showed a mean NAS equal to $69.9 \%$, in five ICUs in two private hospitals, a result which is similar to that found in the present investigation ${ }^{(19)}$. In a post-operative cardiac surgery ICU in another Sao Paulo hospital, a mean of $73.7 \%$ for the NAS was found(20).

However, a study which analyzed adult patients hospitalized in ICUs in two public hospitals and two private hospitals in the city of São Paulo identified mean nursing work load on admission equal to $61.9 \%$ and $52.8 \%$ on the last day of hospitalization - data which is below the present investigation's results ${ }^{(21)}$. Another study on nursing work load in an Adult ICU in the interior of the state of São Paulo identified a mean NAS equal to $62.2 \%$, that is, below what was identified in the present investigation ${ }^{(16)}$.

A study undertaken in Spain in a cardiology ICU identified a mean NAS of $41 \%$, this data being lower than that of the present study, as well as lower than the values found in studies undertaken in Brazil in this type of unit(22). Yet another investigation, this one carried out in a cardiology and neurology ICU in a tertiary São Paulo hospital, found a mean NAS equal to $65.18 \%{ }^{(23)}$.

Of the studies found on the NAS in ICU undertaken in Brazil, only two identified means higher than those of the present investigation; one undertaken in the northwest of the state of Paraná (mean for the NAS of 104\%)(24) and the other carried out in a surgical cardiology ICU in a public teaching hospital in the city of Sao Paulo (daily mean of $74.6 \%)^{(25)}$.

\section{Conclusion}

With the results found, it can be asserted that the NAS instrument was able to provide information concerning the process of caring for patients hospitalized in a Burns ICU, and by applying it, it was identified that there is a high work load, that is, burden for the nursing team of the unit studied.

Although this investigation's results contribute to the advance of knowledge and have achieved the objective proposed, it is important to consider - as limitations of the study - that it was undertaken in only one Burns ICU (not permitting the generalization of the findings), the inexistence of Brazilian studies using the NAS in burns patients hospitalized in ICU, the small sample, and the non-correlation of work load with the

* In Brazil, a 'medium-size' hospital has between 50 and 149 beds. Translator's note. 
variables of age and the patient's clinical conditions, among others.

Thus, it is suggested that further studies in this line be undertaken, with the same characteristics of the population studied, or in multi-centric studies, with the aim of showing the institutions that through the systematized application of the NAS, it is possible to use it as an indicator for work load and, consequently, for assisting in the appropriate dimensioning of the nursing team for the assistance for the patient.

\section{References}

1. Jong AEE, Leeman J, Middelkoop E. Development of nursing work load measurement instrument in burn care. Burns, Guildford. 2009;35(7): 942-8.

2. Panunto MR, Guirarello EB. Carga de trabalho de enfermagem em Unidade de Terapia Intensiva de um hospital de ensino. Acta Paul Enferm. 2012; 25(1):96-101.

3. Trindade LL, Coelho A, Pires de Pires S, ED. Revisão da produção teórica latino-americana sobre cargas de trabalho. Enferm Global. 2013;29:373-82.

4. Queijo AF, Padilha KG. Nursing Activities Score (NAS): adaptação transcultural e validação para a língua portuguesa. Rev EsC Enferm USP. 2009; 43(Esp):1018-25.

5. Miranda DR, Nap R, de Rijk A, Schaufeli W, Iapichino

G. Nursing activities score. Crit Care Med. 2003; 31(2):374-82.

6. Harless DW, Mark BA. Nurse staffing and quality of care with direct measurement of inpatient staffing. Med Care. 2010 Jul;48(7):659-63.

7. Canadian Nurses Association. Measuring nurses' workload. Nursing Now: Issues and trends in Canadian Nurs. [Internet]. 2003; [acesso 13 jun 2013];15(1). Disponível em: http://www2. cna-aiic.ca/CNA/documents/pdf/publications/NN_ NursesWorkloadmarch2003_e.pdf

8. Rossetti AC, Gaidzinski RR, Fugulin FMT. Nursing workload in the emergency department: a methodological proposal. Rev. Latino-Am. Enfermagem. 2013;21(spe):225-32.

9. Ducci AJ, Padilha KG. Nursing activities score: estudo comparativo da aplicação retrospectiva e prospectiva em unidade de terapia intensiva. Acta Paul Enferm. [Internet]. 2008 [acesso 10 jan 2013];21(4):581-7. Disponível em: http://www.scielo.br/scielo.php?script=sci_arttext\& pid=S0103-21002008000400008\&Ing=en. http://dx.doi. org/10.1590/S0103-21002008000400008
10. Leão CEG, Andrade ES, Fabrini DS, Oliveira RA, Machado GLB, Gontijo LC. Epidemiologia das queimaduras no estado de Minas Gerais. Rev Bras Cir Plást. 2011;26(4):573-7.

11. Lacerda LA, Carneiro AC, Oliveira AF, Gragnani A, Ferreira LM. Estudo epidemiológico da Unidade de Tratamento de Queimaduras da Universidade Federal de São Paulo. Rev Bras Queimaduras. 2010;9(3):82-8.

12. Lima LS, Araújo MAR, Cavendish TA, Assis EM, Aguiar G. Perfil epidemiológico e antropométrico de pacientes internados em uma unidade de tratamento de queimados em Brasília, Distrito Federal. Com Ciênc Saúde. 2010;21(4):301-8.

13. Theodorou $P, X u$ W, Weinand C, Perbix W, Maegele $M$, Lefering $R$, et al. Incidence and treatment of burns: $A$ twenty-year experience from a single center in Germany. Burns. 2013;39:49-54.

14. Cunha NT. Complicações das queimaduras In: Maciel E, Serra MC. Tratado de queimaduras. São Paulo: Atheneu; 2006. p. 81-90.

15. Rosa DMC. Epidemiologia, lesão inalatória e biomarcadores: relação com prognóstico de adultos queimados internados em uma unidade de referência. [tese de doutorado]. Botucatu (SP): Faculdade de Medicina de Botucatu da Universidade Estadual Júlio de Mesquita Filho; 2009. 153 p.

16. Panunto MR, Guirarello EB. Carga de trabalho de enfermagem em Unidade de Terapia Intensiva de um hospital de ensino. Acta Paul Enferm. 2012; 25(1):96-101.

17. Gonçalves LA, Garcia PC, Toffoleto MC, Telles SCR, Padilha KG. Necessidades de cuidados de enfermagem em Terapia Intensiva: evolução diária dos pacientes segundo o Nursing Activities Score (NAS). Rev Bras Enferm. 2006;59(1):56-60.

18. Conishi RMY, Gaidzinski RR. Nursing Activities Score (NAS) como instrumento para medir carga de trabalho de enfermagem em UTI adulto. Rev Esc Enferm USP. 2007;41(3):346-54.

19. Gonçalves LA, Padilha KG. Fatores associados à carga de trabalho de enfermagem em Unidade de Terapia Intensiva. Rev Esc Enferm USP. 2007;41(4):645-52.

20. Ducci AJ, Zanei SSV, Whitaker IY. Carga de trabalho de enfermagem para quantificar proporção profissional de enfermagem/paciente em UTI cardiológica. Rev Esc Enferm USP. 2008;42(4):673-80.

21. Silva MCM, Souza RMC, Padilha KG. Factors associated with death and readmission into the Intensive Care Unit. Rev. Latino-Am. Enfermagem. 2011; 19(4):911-9. 
22. Adell $A B$, Campos RA, Cubedo RM, Quintana $B J$, Sanahuja RE, Sanchís MJ, et al. Nursing Activities Score (NAS). Our experience with a nursing load calculation system based on times. Enferm Intens. 2005; 16(4):164-73.

23. Queijo AF, Martins RS, Andolhe R, Oliveira EM, Barbosa RL, Padilha KG. Nursing workload in neurological intensive care units: cross-sectional study. Intensive Crit Care Nurs. 2013;29(2):112-6.

24. Inoue KC, Kuroda CM, Matsuda LM. Nursing activities score (NAS): Carga de trabalho de enfermagem em UTI e fatores associados. Ciênc Cuidado Saúde. 2011;10(1):134-40.

25. Dias MCCB. Aplicação do Nursing Activities Score - N.A.S.: como instrumento de medida de carga de trabalho de enfermagem em UTI Cirúrgica Cardiológica. [dissertação de mestrado]. São Paulo: Escola de Enfermagem da Universidade de São Paulo; 2006. $115 \mathrm{p}$. 